\title{
Comparison of in situ versus in vitro methods of fiber digestion at 120 and 288 hours to quantify the indigestible neutral detergent fiber fraction of corn silage samples
}

\author{
R. W. Bender, D. E. Cook, and D. K. Combs ${ }^{1}$ \\ Department of Dairy Science, University of Wisconsin, Madison 53706
}

\begin{abstract}
Ruminal digestion of neutral detergent fiber (NDF) is affected in part by the proportion of NDF that is indigestible (iNDF), and the rate at which the potentially digestible NDF (pdNDF) is digested. Indigestible NDF in forages is commonly determined as the NDF residue remaining after long-term in situ or in vitro incubations. Rate of pdNDF digestion can be determined by measuring the degradation of NDF in ruminal in vitro or in situ incubations at multiple time points, and fitting the change in residual pdNDF by time with log-transformed linear first order or nonlinear mathematical treatments. The estimate of indigestible fiber is important because it sets the pool size of potentially digestible fiber, which in turn affects the estimate of the proportion of potentially digestible fiber remaining in the time series analysis. Our objective was to compare estimates of iNDF based on in vitro (IV) and in situ (IS) measurements at 2 fermentation end points (120 and 288 h). Further objectives were to compare the subsequent rate, lag, and estimated total-tract NDF digestibility (TTNDFD) when iNDF from each method was used with a 7 time point in vitro incubation of NDF to model fiber digestion. Thirteen corn silage samples were dried and ground through a 1-mm screen in a Wiley mill. A $2 \times 2$ factorial trial was conducted to determine the effect of time of incubation and method of iNDF analysis on iNDF concentration; the 2 factors were method of iNDF analysis (IS vs. IV) and incubation time (120 vs. 288 h). Four sample replicates were used, and approximately $0.5 \mathrm{~g} /$ sample was weighed into each Ankom F57 bag (Ankom Technology, Macedon, NY; pore size $=25 \mu \mathrm{m})$ for all techniques. The IV-120 had a higher estimate of iNDF $(37.8 \%$ of NDF) than IS-120 (32.1\% of NDF), IV-288 (31.2\% of $\mathrm{NDF}$ ), or IS-288 technique (25.7\% of NDF). Each of the estimates of iNDF was then used to calculate the
\end{abstract}

Received August 14, 2015.

Accepted February 2, 2016

${ }^{1}$ Corresponding author: dkcombs@wisc.edu rate of degradation of pdNDF from a 7 time point in vitro incubation. When the IV-120 NDF residue was used, the subsequent rates of pdNDF digestion were fastest $\left(2.8 \% \mathrm{~h}^{-1}\right)$ but the estimate of lag was longest $(10.3 \mathrm{~h})$, compared with when iNDF was based on the IS-120 or IV-288 NDF residues (rates of $2.3 \% \mathrm{~h}^{-1}$ and $2.4 \% \mathrm{~h}^{-1}$; lag times of 9.7 and $9.8 \mathrm{~h}$, respectively). Rate of pdNDF degradation was slowest $\left(2.1 \% \mathrm{~h}^{-1}\right)$ when IS-288 NDF residue was used as the estimate of iNDF. The estimate of lag based on IS-288 (9.4 h) was similar to lag estimates calculated when IS-120 or IV-288 were used as the estimate of iNDF. The TTNDFD estimates did not differ between treatments (35.5\%), however, because differences in estimated pools of iNDF resulted in subsequent changes in rates and lag times of fiber digestion that tended to cancel out. Estimates of fiber digestion kinetic parameters and TTNDFD were similar when fit to either the linear or nonlinear fiber degradation models. All techniques also yielded estimates of iNDF that were higher than predicted iNDF based on the commonly used ratio of $2.4 \times$ lignin.

Key words: fiber digestion, indigestible neutral detergent fiber, lignin

\section{INTRODUCTION}

Neutral detergent fiber concentration of forages varies from 30 to $80 \%$ of DM and also can differ widely in digestibility. Forage NDF consists of 2 fractions: an indigestible fraction (iNDF) and a potentially digestible fraction ( $\mathbf{p d N D F}$ ). The potentially digestible fraction disappears from the rumen either by microbial digestion or passage, whereas the indigestible NDF fraction leaves the rumen only by passage (Mertens, 1993). Therefore, to model the digestion kinetics of pdNDF, accurate prediction of the iNDF fraction is a critical first step in determining the digestibility of the forage.

The iNDF fraction is commonly estimated as 2.4 times the ADL content, as originally proposed by Mertens (1973) and Chandler et al. (1980) and discussed in Van Soest et al. (2005). However, others have shown that iNDF determination by this method does not correlate well to estimates of iNDF determined from long-term 
in vitro (IV) or in situ (IS) incubations (Huhtanen et al., 2006; Kramer et al., 2010; Krizsan and Huhtanen, 2013). The iNDF fraction can be approximated using a measurement of undigested NDF (uNDF) remaining at a predetermined incubation time, such as 96, 120, or $216 \mathrm{~h}$, in either an IV or IS system (Van Soest et al., 2005; Schalla et al., 2012; Krizsan and Huhtanen, 2013). Others propose that longer incubation times are required to precisely estimate the iNDF concentration of a feed (Nousiainen et al., 2004). The Nordic Feed Evaluation System (NorFor) defines iNDF as the NDF residue remaining after $288 \mathrm{~h}$ of IS incubation (NorFor, 2011). Throughout this manuscript, the authors use the term iNDF when referring to the intrinsic characteristic of the forage, and UNDF when referring to the amount of NDF undigested at a particular time point.

Ruminal fiber digestion is a competitive process of passage and digestion. The rate of ruminal fiber digestion of the pdNDF can be estimated by measuring the change in pdNDF from IV incubations at 24, 30, and $48 \mathrm{~h}$ (Lopes et al., 2015c). However, a more common approach is to index the relative fiber digestibility from a single time point IV incubation, most often a 30 or $48 \mathrm{~h}$. This method fails to account for variations in retention time of NDF in the rumen, as well as the inherent variation in lag times of IV digestion assays. In addition, Lopes et al. (2015c) found no correlation between in vivo NDF digestibility and the 30-h NDF digestibility (NDFD) over 21 diets from 7 research trials conducted at the University of Wisconsin-Madison. However, Lopes et al. (2015a,b) reported that the totaltract NDF digestibility (TTNDFD) can be predicted by IV incubation of forage samples at several time points using the predetermined endpoint of digestion (iNDF) and measuring the rate of fiber digestion (kd).

The objectives of the present study were to compare estimates of iNDF determined by 2 methods (IS and IV) at 2 different time points (120 and $288 \mathrm{~h}$ ); compare the subsequent rate, lag, iNDF/lignin ratio, and TTNDFD; and evaluate the quality of fit between 2 models of fiber digestion. In the first model the lag and the rate of pdNDF degradation were determined as the slope of the natural logarithm-transformed fractions of pdNDF versus time. The second method of model fitting was done using a nonlinear procedure to calculate lag, digestion rate, and iNDF.

\section{MATERIALS AND METHODS}

The IS and IV studies were conducted at the University of Wisconsin-Madison using dairy cows housed in the Arlington Blaine Dairy. Animal protocols were approved by the Institutional Animal Care and Use Committee in the College of Agricultural and Life
Sciences. The IS uNDF data were generated using 4 ruminally cannulated late lactation dairy cows fed a high forage TMR diet (44.5\% alfalfa silage, $26.8 \%$ corn silage, $10.7 \%$ alfalfa hay, $6.5 \%$ straw, $11.5 \%$ concentrate mix; DM basis) with a measured nutrient composition of $14.7 \% \mathrm{CP}, 46.1 \% \mathrm{NDF}, 10.6 \%$ starch, and $3.4 \%$ ether extract.

Thirteen corn silage samples were obtained from a commercial forage testing laboratory (Rock River Laboratory Inc., Watertown, WI), where they were analyzed for CP, starch, and ether extract by NIR analysis for general characterization of the corn silage. Samples were dried at $60^{\circ} \mathrm{C}$ for $48 \mathrm{~h}$ in a forced-air oven to determine DM content. Dried samples were ground to pass a 1-mm Wiley mill (Arthur H. Thomas, Philadelphia, PA) screen, and $0.5 \mathrm{~g} /$ sample was weighed into each Ankom F57 bag (Ankom Technology, Macedon, NY) with a pore size of $25 \mu \mathrm{m}$ for all IV and IS samples for both the uNDF and NDFD assays. Acid detergent lignin (ash-free) was determined via method 973.18 (AOAC, 2006), modified to use $1.0 \mathrm{~g}$ per sample in each Ankom F57 bag (Ankom Technology). All Ankom bags were washed in acetone, dried in a fume hood, and further dried in a forced-air oven at $60^{\circ} \mathrm{C}$ for $1 \mathrm{~h}$ before weighing the sample.

A $2 \times 2$ factorial trial was conducted to determine the uNDF residue, with method of analysis (IS vs. IV) and incubation time (120 vs. $288 \mathrm{~h}$ ) as factors, creating the 4 treatment groups (IS-120, IS-288, IV-120, IV-288).

For each of the 13 samples and 2 incubation times, the aforementioned bags filled with each sample were inserted into a nylon laundry bag $(30 \times 40 \mathrm{~cm})$ in duplicate and then positioned in the ventral rumen of each cow. Bags were pre-soaked in warm water for approximately $30 \mathrm{~min}$ before incubation. Each laundry bag contained 8 blank, sealed Ankom bags containing 0 $\mathrm{g}$ of sample to correct for any infiltration of NDF into the sample bags. Samples were removed after 120 or 288 h. After removal, samples were soaked in cold water before washing twice in a commercial washing machine with cold water during 12 -min cycles to ensure that no residue adhered to the bag. This procedure was then duplicated in a second run.

The IV uNDF data were determined by using the Combs-Goeser standardized IV incubation technique (Goeser and Combs, 2009; Goeser et al., 2009), modified to remove bags at 2 time points (120 and $288 \mathrm{~h}$ ), instead of the original 3 (24, 30, and $48 \mathrm{~h})$. Each of the 13 samples and 2 time point combinations were duplicated within a run and replicated in 2 runs. Each replicate contained 8 blank Ankom bags containing $0 \mathrm{~g}$ of sample to correct for infiltration of NDF into the bag. After removal, $0 \mathrm{~h}$ time point samples were included and rinsed in cold water. 
The NDF digestibility was determined by the IV incubation technique described by Goeser and Combs (2009) and Goeser et al. (2009). The procedure was modified to remove bags at 7 time points $(12,18,24$, 30, 36, 42, and $48 \mathrm{~h}$ ). All 13 samples at each time point in the IV incubation technique were replicated in 4 separate runs. Each replicate contained 4 blank Ankom bags containing $0 \mathrm{~g}$ of sample to correct for any infiltration of NDF into the sample bags, as well as $0 \mathrm{~h}$ time point samples to correct for initial NDF content.

The NDF content of the intact sample and digested residue samples was determined by refluxing in neutral detergent solution containing $\alpha$-amylase (Ankom Technology) and sodium sulfite (Sigma-Aldrich, St. Louis, MO) prepared using the procedure described by Goering and Van Soest (1970) and adapted for an Ankom ${ }^{200}$ Fiber Analyzer (Ankom Technology). Neutral detergent fiber percentages of all samples were determined using the following equation:

$\mathrm{NDF}(\mathrm{g} / \mathrm{g}$ of $\mathrm{DM})=[($ bag weight + residue $)$

- (bag weight $\times$ bag correction factor $)] /[$ (bag weight

$$
+ \text { sample }) \text { - (bag weight)]. }
$$

The bag correction factor represents the average fractional weight change of 20 Ankom bags following the NDF wash procedure.

The IV NDF digestibility at each time point was determined using the following equations:

$$
\begin{gathered}
\text { ivNDFD }(\mathrm{g} / \mathrm{g} \text { of } \mathrm{NDF})= \\
\left(\mathrm{NDF}_{0 \mathrm{~h}}-\mathrm{NDF}_{\text {residue }}\right) /\left(\mathrm{NDF}_{0 \mathrm{~h}}\right) ; \\
\operatorname{ivNDFD}(\mathrm{g} / \mathrm{g} \text { of pdNDF })= \\
\left(\mathrm{NDF}_{0 \mathrm{~h}}-\mathrm{NDF}_{\text {residue }}\right) /\left(\% \mathrm{pdNDF} \times \mathrm{NDF}_{0 \mathrm{~h}}\right) .
\end{gathered}
$$

For data sets using the linear model fitting techniques, potentially digestible NDF (pdNDF) as a fraction of NDF was calculated using equation [2], where the NDF residue is the residue at the 120 or $288 \mathrm{~h}$ time point. For data sets using the nonlinear model fitting techniques, iNDF was estimated using a best fit model. The measured uNDF value will be close to the actual iNDF of the sample; therefore, we bound the iNDF to $\pm 10 \%$ of the measured uNDF to ensure the calculated iNDF is not biased too severely by earlier time points. In addition, this allows for an estimation of the true iNDF from measured values. Therefore the pdNDF in the nonlinear model fitting was estimated in the model and was the difference between NDF and iNDF.

To assess rate of digestion, the NDFD assay runs were fit to the following linear first-order differential equations:

$$
f(t)=1
$$

for $t<L$;

$$
f(t)=e^{k d(t-L)}
$$

for $t \geq L$;

$$
R(t)=(1-\mathrm{iNDF}) \times\left(1-e^{k d(t-L)}\right)
$$

for $t \geq L$ and where uNDF $(120$ or 240$) \times 0.9<\mathrm{iNDF}$ $<\mathrm{uNDF}(120$ or 240$) \times 1.1$. For equations [4], [5], and [6], $f(t)=$ remaining pdNDF $(\mathrm{g} / \mathrm{g})$ at time $t ; R(t)=$ NDF degraded $(\mathrm{g} / \mathrm{g})$ at time $t ; k d=$ constant fractional rate of digestion; $t=$ time $(\mathrm{h})$; and $L=$ lag time before digestion occurs.

The assay results were fit to a linear (equations [4] and [5]) and a nonlinear (equations [4] and [6]) equation. In the first method, the natural logarithm of the fractional pdNDF residue in each bag was calculated. The slope of the natural logarithm-transformed fractions versus time function is linear; thus, the fractional rate of disappearance of pdNDF and the intercept (lag) of digestion can be determined. The slope and intercept was calculated using $\mathrm{R}^{2}$ as the measure of best fit, thus minimizing the transformed errors from the model. At long incubation times, a time point result for remaining pdNDF $(\mathrm{g} / \mathrm{g})$ can be negative. In this circumstance, the natural logarithm transformation cannot be completed and the time point cannot be used. In addition, when the residual NDF fraction is close to 0, the logtransformed value is a large negative number that exaggerates the actual slope of digestion. Thus, we removed all residue values that were less than an arbitrary threshold of 0.05 . This 0.05 threshold was also applied at the opposite end; samples that had not achieved $5 \%$ of pdNDF degradation were not used because they could not be distinguished from samples that had not yet passed the lag phase. Another consequence of this method is that methods of iNDF measurement yielding a larger iNDF fraction (such as IV and earlier time points), and therefore a smaller pdNDF fraction, yield more data points being discarded for being too close to the iNDF estimate. After the data were best fit, the entire run was discarded as flawed if the goodness of fit, here measured by $\mathrm{R}^{2}$, was less than 0.5 . Of 52 total runs, 2 were entirely discarded. Thus, in the linear fit model, the measured uNDF values were used as the endpoint of digestion.

The second method of model fitting was done using the NLIN procedure in SAS (version 9.3, SAS Institute Inc.), which calculated the lag, digestion rate, and the 
Table 1. Nutrient composition and NDF digestion parameters of 13 corn silage samples used for analysis (\% of DM unless otherwise indicated)

\begin{tabular}{lcccc}
\hline Item & Average & SD & Minimum & Maximum \\
\hline DM (\% of as fed) & 39.2 & 7.3 & 26.6 & 55.6 \\
CP & 8.5 & 1.2 & 7.1 & 10.9 \\
Starch & 27.7 & 9.0 & 14.0 & 38.0 \\
NFC & 41.8 & 6.2 & 32.1 & 49.7 \\
Ether extract & 2.1 & 0.3 & 1.4 & 2.5 \\
NDF & 36.8 & 4.8 & 29.7 & 45.2 \\
Lignin & 2.8 & 0.7 & 1.9 & 4.9 \\
Ash-free lignin & 2.0 & 0.4 & 2.3 & 34.5 \\
uNDF & (\% of NDF) & 6.0 & 13.2 & 0.9 \\
kd $^{2}$ & 25.6 & 0.5 & 3.0 & 49.0 \\
TTNDFD $^{3}$ & 2.1 & 6.2 & 23.6 & \\
\hline
\end{tabular}

${ }^{1}$ Undigested NDF determined via in situ incubation for $288 \mathrm{~h}$.

${ }^{2}$ Rate of ruminal degradation of pdNDF (kd) determined using iNDF (in situ $288 \mathrm{~h}$ ) as an endpoint of fermentation.

${ }^{3}$ Total-tract NDF digestibility (TTNDFD, g of NDF digested/g of NDF, \%) determined as previously reported (Lopes et al., 2015c).

iNDF. The NLIN procedure iteratively solves for the constants in the model by using nonlinear least squares, minimizing the sum of squared errors (SSE) for the real errors, rather than the transformed errors of the linear method of model fitting. Using this modeling technique, the iNDF was estimated as part of the model best fit, but was bounded to be within $10 \%$ of the measured uNDF120 or uNDF288 (equation [6]). As with the previous linear model fitting approach, NDFD time points with pdNDFD residues of less than 0.05 or greater than 0.95 were rejected.

Digestion rate, lag, quality of fit $\left(\mathrm{R}^{2}\right)$, and an estimate of total-tract fiber digestibility (TTNDFD) was calculated using the different pdNDF values yielded by each UNDF assay from each combination of method of analysis and incubation time as well as the NDFD values from the IV incubation technique. The TTNDFD is calculated by the following equation (Lopes et al., 2015c):

$$
\mathrm{TTNDFD}=\operatorname{pdNDF} \times \frac{k}{k-2.67} \times \frac{1}{0.9},
$$

where $k=$ digestion rate of pdNDF $(\% / \mathrm{h}) ; 2.67$ represents the pdNDF passage rate $\left(\mathrm{k}_{\mathrm{p}}\right)$ from the reticulorumen $(\% / \mathrm{h})$; and 0.9 represents the proportion of fiber digestion that occurs in the reticulorumen.

All data were analyzed via the MIXED procedure of SAS (version 9.3, SAS Institute Inc.) with the final model including the effects of method of analysis (IS vs. IV), incubation time, and interaction between method of analysis and incubation time. Fixed effects for sample number and the interaction of sample number by method of analysis by incubation time were removed from the model $(P>0.25)$. Significance was declared when $P<0.05$ and a tendency at $0.05<P<0.10$. In addition, a contrast was conducted to compare ruminal digestion parameters for the 4 treatments estimating iNDF to the $2.4 \times$ ash-free lignin iNDF estimation.

\section{RESULTS}

Descriptive information of the nutrient composition and NDF digestion parameters of the corn silage samples included in the analyses are provided in Table 1. Nutrient composition is typical of commercially produced corn silages used on dairy farms in the Midwest United States.

The effect of method of digestion and incubation length on ruminal digestion parameters in both a linear and nonlinear model fitting approach is displayed in Table 2. For the linear model fit, the uNDF fraction as a proportion of total NDF was greater $(P<0.001)$ for the IV compared with the IS treatment ( 34.5 vs. $28.9 \%$, respectively). In addition, the longer incubation time resulted in a lower $(P<0.001)$ uNDF fraction $(28.4$ vs. $35.0 \%, 288$ and $120 \mathrm{~h}$, respectively). As a result, the uNDF fraction estimated from the IV-120 treatment was greater, and the IS-288 estimated UNDF was lower, compared with the remaining treatments. The calculated ratio of uNDF divided by ash-free lignin content had both a method $(P<0.001 ; 5.4$ vs. 4.5 , IV and IS, respectively) and time $(P<0.001 ; 4.4$ vs. $5.5,288$ and $120 \mathrm{~h}$, respectively) effect. Similarly, the IV-120 treatment had a significantly greater, and the IS-288 treatment a significantly lower, uNDF divided by ashfree lignin ratio when compared with the remaining treatments.

The rate of ruminal pdNDF digestion $(\% / \mathrm{h})$, lag (h), quality of fit $\left(\mathrm{R}^{2}\right)$, and TTNDFD estimate ( $\mathrm{g}$ of NDF digested/g of NDF, \%) are displayed in Table 2 and were determined using the IV NDFD digestibilities 
$(12,18,24,30,36,42$, and $48 \mathrm{~h})$ and the endpoints of uNDF from each treatment explained above. For the linear model, the rate was significantly greater for the IV compared with the IS treatment $(2.4$ vs. $2.1 \% / \mathrm{h}$, respectively). In addition, the shorter incubation time for uNDF resulted in a faster $(P<0.001)$ digestion rate (2.6 vs. $2.3 \% / \mathrm{h}, 120$ and $288 \mathrm{~h}$, respectively). As a result, the IV-120 treatment had a significantly greater, and the IS-288 treatment a significantly lower, digestion rate when compared with the remaining treatments. No main effect was found of method or time on lag, but the IV-120 treatment was greater $(P<0.05)$ compared with the IS-288 treatment. The quality of fit, as measured by $\mathrm{R}^{2}$, did not differ among treatments and averaged 0.87 across all treatments. Similarly, the TTNDFD did not differ among treatments and averaged $35.5 \%$. No interactions between method and time were observed for any ruminal digestion parameters in the linear approach.

For the nonlinear approach, the data followed the same general pattern as the linear model for both the rate and iNDF fraction as a proportion of total NDF. The uNDF fraction as a proportion of total NDF was greater $(P<0.001)$ for the IV compared with the IS treatment (32.0 vs. $26.6 \%$, respectively). In addition, the longer incubation time resulted in a lower $(P<$ $0.001)$ uNDF fraction (27.1 vs. $31.5 \%, 288$ and $120 \mathrm{~h}$, respectively). As a result, the IV-120 treatment had a greater, and the IS-288 treatment a lower, uNDF fraction when compared with the remaining treatments. The rate was greater for the IV compared with the IS treatment ( 2.3 vs. $2.0 \% \mathrm{~h}^{-1}$, respectively). In addition, the shorter incubation time resulted in a lower $(P=$
$0.002)$ digestion rate $\left(2.2\right.$ vs. $2.0 \% \mathrm{~h}^{-1}, 120$ and $288 \mathrm{~h}$, respectively). As a result, the IV-120 treatment had a greater, and the IS-288 treatment a lower, digestion rate when compared with the remaining treatments. No main effect was found of method or time on lag in the nonlinear approach. Similar to the linear approach, the TTNDFD estimate did not differ among treatments and averaged $34.2 \%$. No interactions between method and time were observed for any ruminal digestion parameters in the nonlinear approach.

Table 3 provides a comparison of the ruminal digestion parameters using the laboratory determined estimation of iNDF compared with an estimated iNDF pool $(2.4 \times$ ash-free lignin). The estimate of indigestible $\mathrm{NDF}$, digestion rate of pdNDF, and lag time as a result of using $2.4 \times$ ash-free lignin to estimate iNDF, were significantly lower than when estimated by the other 4 methods. The calculated TTNDFD values however, were similar.

\section{DISCUSSION}

Wide variations exist in methodologies in commercial feed testing laboratories for testing NDF digestion rate (Van Amburgh et al., 2005; Tylutki et al., 2008; Goeser et al., 2009) and iNDF (Nousiainen et al., 2004; Van Soest et al., 2005; Kramer et al., 2010; Krizsan and Huhtanen, 2013). This study evaluated methods of estimating iNDF, including IV and IS at 2 incubation time points (120 and $288 \mathrm{~h}$ ), and its subsequent effects on estimating the ruminal fiber digestibility using both a linear and a nonlinear modeling approach. The study included 13 corn silages selected to be diverse in

Table 2. Effect of digestion method (in situ vs. in vitro) and incubation length (120 vs. $288 \mathrm{~h})$ on ruminal digestion parameters in both a linear and nonlinear model fitting approach

\begin{tabular}{|c|c|c|c|c|c|c|c|c|}
\hline \multirow[b]{2}{*}{ Item } & \multicolumn{4}{|c|}{ Treatment } & \multirow[b]{2}{*}{ SEM } & \multicolumn{3}{|c|}{$P$-value } \\
\hline & IS-120 & IS-288 & IV -120 & IV-288 & & Method & Time & Method $\times$ time \\
\hline \multicolumn{9}{|l|}{ Linear model fit } \\
\hline $\mathrm{uNDF}^{1}(\%$ of NDF$)$ & $32.1^{\mathrm{b}}$ & $25.7^{\mathrm{c}}$ & $37.8^{\mathrm{a}}$ & $31.2^{\mathrm{b}}$ & 1.8 & $<0.001$ & $<0.001$ & 0.82 \\
\hline uNDF/ash-free lignin & $5.7^{\mathrm{b}}$ & $4.6^{\mathrm{c}}$ & $6.9^{\mathrm{a}}$ & $5.5^{\mathrm{b}}$ & 0.2 & $<0.001$ & $<0.001$ & 0.54 \\
\hline $\mathrm{kd}^{2}(\% / \mathrm{h})$ & $2.3^{\mathrm{b}}$ & $2.1^{\mathrm{a}}$ & $2.8^{\mathrm{c}}$ & $2.4^{\mathrm{b}}$ & 0.2 & $<0.001$ & $<0.001$ & 0.22 \\
\hline $\operatorname{Lag}(\mathrm{h})$ & $9.7^{\mathrm{ab}}$ & $9.4^{\mathrm{b}}$ & $10.3^{\mathrm{a}}$ & $9.8^{\mathrm{ab}}$ & 0.6 & 0.10 & 0.18 & 0.75 \\
\hline $\mathrm{R}^{2}$ & 0.87 & 0.87 & 0.86 & 0.87 & 0.02 & 0.51 & 0.58 & 0.84 \\
\hline TTNDFD $^{3}$ (\% of NDF) & 35.5 & 35.7 & 35.3 & 35.5 & 1.5 & 0.73 & 0.76 & 0.95 \\
\hline \multicolumn{9}{|l|}{ Nonlinear model fit } \\
\hline $\mathrm{uNDF}^{4}(\%$ of NDF $)$ & $28.7^{\mathrm{b}}$ & $24.5^{\mathrm{c}}$ & $34.3^{\mathrm{a}}$ & $29.8^{\mathrm{b}}$ & 1.7 & $<0.001$ & $<0.001$ & 0.78 \\
\hline $\mathrm{kd}^{2}(\% / \mathrm{h})$ & $2.1^{\mathrm{b}}$ & $1.9^{\mathrm{a}}$ & $2.4^{\mathrm{c}}$ & $2.2^{\mathrm{b}}$ & 0.1 & $<0.001$ & $<0.001$ & 0.69 \\
\hline Lag (h) & 8.7 & 8.5 & 9.0 & 8.8 & 0.6 & 0.43 & 0.59 & 0.99 \\
\hline TTNDFD $^{3}(\%$ of NDF) & 34.3 & 34.6 & 33.7 & 34.2 & 1.4 & 0.37 & 0.42 & 0.85 \\
\hline
\end{tabular}

\footnotetext{
${ }^{\mathrm{a}-\mathrm{c}}$ Within response parameter, means with different superscripts differ $(P<0.05)$.

${ }^{1} \mathrm{uNDF}=$ undigested NDF.

${ }^{2}$ Rate of digestion of potentially digestible NDF.

${ }^{3}$ Total-tract NDF digestibility (TTNDFD, g of NDF digested/g of NDF, \%) determined as previously reported (Lopes et al., 2015c).

${ }^{4}$ Estimated using the NLIN procedure of SAS (version 9.4, SAS Institute Inc., Cary, NC).
} 
composition to measure effects across a wide range of corn silage quality.

Contrary to previous studies which use 3 time points (Goeser et al., 2009) to measure rate of pdNDF degradation, we used 7 time points $(12,18,24,30,36$, 42 , and $48 \mathrm{~h}$ ) in the present study. These time points were chosen because they represented points between the expected assay lag time and the last traditional time point $(48 \mathrm{~h})$ since we sought to determine the best possible fit of the data. We chose time points earlier than the traditional approaches because the physiologically relevant period of ruminal fiber digestion is earlier (Waldo et al., 1972), when a greater mass of fiber is present in the rumen. In addition, because inter-run variation was expected to be substantially greater than intra-sample variation (Mehrez and Orskov, 1977), in lieu of duplication of samples within run for each time point, duplication was completed across more runs. In a commercial laboratory, where turnaround time is of great importance, this may not be a viable strategy, but accounting for interrun variation is important.

In addition to the traditional log-linear transformation to fit the data, our study also evaluated the use of a nonlinear approach. In this approach, we removed from the analysis any time point value where pdNDF residue was $<0.05$ or $>0.95$ of the initial estimate of pdNDF because it cannot be determined whether or not these samples have substantially started or finished digestion at this point. Another feature of the nonlinear iterative solving approach is that the iNDF can be estimated without doing an UNDF assay because adding a pdNDF term to the model will result in a solved value for iNDF. However, we recognize that an iNDF value estimated from a model is still not as good as a measured value. To have a reasonable compromise between model fitting to solve for the degradation asymptote and not allow early time points (subject to variance) to poorly fit the asymptote, we put a limit on the modeled value of the asymptote; in this model the iNDF was bound to a range of $\pm 10 \%$ of the uNDF measured from the assay. If an IV-120 is used as the iNDF estimate, it may be more appropriate to bound the value using a range of zero to some level of overestimation limit, as the IV-120 was found to be significantly lower than the "gold standard" IS-288. In this study, all were treated equally with a $\pm 10 \%$ range.

Accurate estimation of the pool size of pdNDF is important to determining NDF digestibility (Robinson et al., 1986). Different digestion methods (IV and IS) yielded different estimates of the pdNDF pool at different time points. When the estimated value was close to the true pdNDF, overestimations of iNDF yielded overestimations of the digestion rate (Mertens, 1993) that effectively offset each other, resulting in the similar TTNDFD values (Table 2 ). When the estimations were not close, as in the scenarios depicted in Table 3, an estimation from lignin would result in approximately half the iNDF as measured by the 4 IS or IV digestion assays. Thus, based on the present study, we recommend discontinuance of iNDF estimates from lignin for corn silage and recommend the use of IS or IV digestion assays to make the iNDF estimation.

The nonlinear model fit yielded similar but slightly lower results for TTNDFD. This may be due to selection criteria for individual runs being invalid, or due the inherent nature of the linear fit having transformed results that skew it toward higher digestion rates. However, the values were sufficiently close to that of the linear model, that no practical difference can be inferred. Most of the fiber-derived energy is in the early stages of digestion (Waldo et al., 1972). Therefore, we recommend using the nonlinear model fitting techniques to best fit a model with measured values from earlier stages of digestion. However, the linear fit method yielded similar results and we therefore feel it is an acceptable method; if outlier data points are removed, that would otherwise skew the results.

Table 3. Comparison of ruminal digestion parameters determined using undigested NDF (uNDF $)^{1}$ and a loglinear model fit to digestion parameters determined using an estimated indigestible NDF (iNDF) pool from ash-free lignin $(2.4 \times$ lignin $)$ and a log-linear model fit

\begin{tabular}{|c|c|c|c|c|c|}
\hline \multirow[b]{2}{*}{ Item } & \multicolumn{2}{|c|}{$\begin{array}{c}\text { Four treatments } \\
\text { averaged }\end{array}$} & \multicolumn{2}{|c|}{$2.4 \times$ lignin } & \multirow[b]{2}{*}{$P$-value } \\
\hline & Mean & SEM & Mean & SEM & \\
\hline iNDF ( $\%$ of NDF) & 30.7 & 1.4 & 13.5 & 1.6 & $<0.001$ \\
\hline $\mathrm{kd}^{2}(\% / \mathrm{h})$ & 2.4 & 0.1 & 1.6 & 0.1 & $<0.001$ \\
\hline Lag $(\mathrm{h})$ & 9.7 & 0.6 & 7.8 & 0.7 & 0.01 \\
\hline TTNDFD $^{3}(\%$ of NDF) & 35.3 & 1.5 & 35.2 & 1.6 & 0.91 \\
\hline
\end{tabular}


Criteria for removing individual time points and runs need to be employed as a quality assurance standard for any highly variable assay such as fiber digestion. The linear model choice of an $\mathrm{R}^{2}$ of greater than 0.5 is quite conservative for inclusion. In a large data set of random decreasing values, this same model yielded a mean $\mathrm{R}^{2}$ value of 0.89 , and only 5 runs were below this 0.50 threshold. Thus, the criteria described herein for selection of valid time points and runs are a good starting point. Run-to-run variation was a highly significant $(P<0.001)$ fixed effect in all models for both rate and lag. As such, we recommend duplicating across more runs, rather than duplicating within run.

The real value that producers and field nutritionists want to know is how much energy will a group of cattle derive from a particular fiber source. This can be determined via the TTNDFD. It accomplishes this by taking estimations of rate and the potentially digestible NDF fraction in the ruminant, and in combination with assumed passage rates and postruminal degradation rates, provides a value that is a reasonable estimation of fiber digestion (Lopes et al., 2015c). It was also found to be a robust measurement across iNDF assay methods, yielding substantially similar results, regardless of assay method.

\section{ACKNOWLEDGMENTS}

The authors thank the Rock River Laboratory Inc. (Watertown, WI) for providing the corn silage samples. In addition, special thanks go to Fernanda Lopes, Kathryn Ruh, and Sandra Bertics (University of Wisconsin Dairy Science) for laboratory assistance and John Goeser (Rock River Laboratories Inc.) for technical assistance. This project was funded in part with USDA Hatch Multi-State Research Formula Fund \#WIS01635 (Madison, WI).

\section{REFERENCES}

AOAC. 2006. Official methods of analysis. 18th ed. Assoc. Off. Anal. Chem., Arlington, VA.

Chandler, J. A., W. J. Jewell, J. M. Gossett, P. J. Van Soest, and J. B. Robertson. 1980. Predicting methane fermentation biodegradability. Pages 93-107 in J. Biotech. and Engineering Symp. No. 10, John Wiley \& Sons, Hoboken, NJ.

Goering, H. K., and P. J. Van Soest. 1970. Forage Fiber Analyses (Apparatus, Reagents, Procedures, and Some Applications). Agric. Handbook No. 379. ARS-USDA. Washington, DC.

Goeser, J. P., and D. K. Combs. 2009. An alternative method to assess 24 -h ruminal in vitro neutral detergent fiber digestibility. J. Dairy Sci. 92:3833-3841.

Goeser, J. P., P. C. Hoffman, and D. K. Combs. 2009. Modification of a rumen fluid priming technique for measuring in vitro neutral detergent fiber digestibility. J. Dairy Sci. 92:3842-3848.
Huhtanen, P., J. Nousiainen, and M. Rinne. 2006. Recent developments in forage evaluation with special reference to practical applications. Agric. Food Sci. 15:293-323.

Kramer, M., M. R. Weisbjerg, and P. Lund. 2010. Estimation of indigestible NDF in feedstuffs for ruminants. Pages 15-20 in Proc. 1st Nordic Feed Science Conf., Uppsala, Sweden. SLU Repro, Uppsala, Sweden.

Krizsan, S. J., and P. Huhtanen. 2013. Effect of diet composition and incubation time on feed indigestible neutral detergent fiber concentration in dairy cows. J. Dairy Sci. 96:1715-1726.

Lopes, F., D. E. Cook, and D. K. Combs. 2015a. Effects of varying dietary ratios of corn silage to alfalfa silage on digestion of neutral detergent fiber in lactating dairy cows. J. Dairy Sci. 98: http:// dx.doi.org/10.3168/jds.2014-8662. In press.

Lopes, F., D. E. Cook, and D. K. Combs. 2015b. Validation of an in vitro model for predicting rumen and total-tract fiber digestibility in dairy cows fed corn silages with different in vitro neutral detergent fiber digestibilities at 2 levels of dry matter intake. J. Dairy Sci. 98:574-585.

Lopes, F. K. Ruh, and D. K. Combs. 2015c. Validation of an approach to predict total tract fiber digestibility using the standardized in vitro technique in different diets fed to dairy cows. J. Dairy Sci. 98:2596-2602.

Mehrez, A. Z., and E. R. Orskov. 1977. A study of the artificial fibre bag technique for determining the digestibility of feeds in the rumen. J. Agric. Sci. 88:645-650.

Mertens, D. R. 1973. Application of the theoretical mathematical models to cell wall digestion and forage intake in ruminants. $\mathrm{PhD}$. Diss., Cornell Univ., Ithaca, NY.

Mertens, D. R. 1993. Rate and extent of digestion. Pages 13-51 in Quantitative Aspects of Ruminant Digestion and Metabolism. J. M. Forbes and J. France, ed. CAB International, Oxon, UK.

NorFor. 2011. The Nordic feed evaluation system. European Federation of Animal Science, Wageningen Academic Publishers, Wageningen, UK.

Nousiainen, J., S. Ahvenjarvi, M. Rinne, M. Hellamaki, and P. Huhtanen. 2004. Prediciton of indigestible cell wall fraction of grass silage by near infrared reflectance spectroscopy. Anim. Feed Sci. Technol. 115:295-311.

Robinson, P. H., J. G. Fadel, and S. Tamminga. 1986. Evaluation of mathematical models to describe neutral detergent residue in terms of its susceptibility to degradation in the rumen. Anim. Feed Sci. Technol. 15:249-271.

Schalla, A., L. Meyer, Z. Meyer, S. Onetti, A. Schultz, and J. Goeser. 2012. Hot topic: Apparent total-tract digestibilities measured commercially using 120-hour in vitro indigestible neutral detergent fiber as a marker are related to commercial dairy cattle performance. J. Dairy Sci. 95:5109-5114.

Tylutki, T. P., D. G. Fox, V. M. Durbal, L. O. Tedeschi, J. B. Russell, M. E. Van Amburgh, T. R. Overton, L. E. Chase, and A. N. Pell. 2008. Cornell Net Carbohydrate and Protein System: A model for precision feeding of dairy cattle. Anim. Feed Sci. Technol. 143:174-202.

Van Amburgh, M. E., P. J. Van Soest, J. B. Robertson, and W. F. Knaus. 2005. Corn silage netural detergent fiber: Refining a mathematical approach for in vitro rates of digestion. 2005 Cornell Nutrition Conference. Syracuse, NY.

Van Soest, P. J., M. E. Van Amburgh, J. B. Robertson, and W. F. Knaus. 2005. Validation of the 2.4 times lignin factor for ultimate extent of NDF digestion, and curve peeling rate of fermentation curves into pools. 2005 Cornell Nutrition Conference for Feed Manufacturers, Syracuse, NY.

Waldo, D. R., L. W. Smith, and E. L. Cox. 1972. Model of cellulose disappearance from the rumen. J. Dairy Sci. 55:125-129. 